\title{
Increased TNF- $\alpha$, IL-6 and decreased IL-1 $\beta$ immunohistochemical expression by the stromal spindle-shaped cells in the central giant cell granuloma of the jaws
}

\author{
Panagiota Papanicolaou ${ }^{1}$, Evanthia Chrysomali ${ }^{2}$, Evangelia Stylogianni ${ }^{3}$, Catherine Donta ${ }^{4}$, Dimitris Vla- \\ chodimitropoulos 5
}

\author{
${ }^{1}$ DDS, McS, DrDent. Clinical Assistant, Department of Oral and Maxillofacial Surgery, School of Dentistry, University of Ath- \\ ens, Athens, Greece \\ ${ }^{2}$ DDS, DrDent. Assistant Professor, Department of Oral Pathology, School of Dentistry,University of Athens, Athens, Greece \\ ${ }^{3}$ DDS, DrDent. Assistant Professor, Department of Oral and Maxillofacial Surgery, School of Dentistry,University of Athens, \\ Athens, Greece \\ ${ }^{4}$ DDS, DrDent. Assistant Professor, Department of Oral Diagnosis and Radiology, School of Dentistry,University of Athens, \\ Athens, Greece \\ ${ }^{5}$ MD, Dr.Med. Assistant Professor, Laboratory of Forensic Medicine and Toxicology, Medical School, University of Athens, \\ Athens, Greece
}

Correspondence:

Laskareos 55, 114-73

Athens, Greece

peppyppncl@yahoo.gr

Received: $14 / 07 / 2010$

Accepted: 02/05/2011

Papanicolaou P, Chrysomali E, Stylogianni E, Donta C, Vlachodimitropoulos D. Increased TNF- $\alpha$, IL-6 and decreased IL-1 $\beta$ immunohistochemical expression by the stromal spindle-shaped cells in the centralgiant cell granuloma of the jaws. Med Oral Patol Oral Cir Bucal. 2012 Jan 1;17 (1):e56-62.

http://www.medicinaoral.com/medoralfree01/v17i1/medoralv17ilp56.pdf

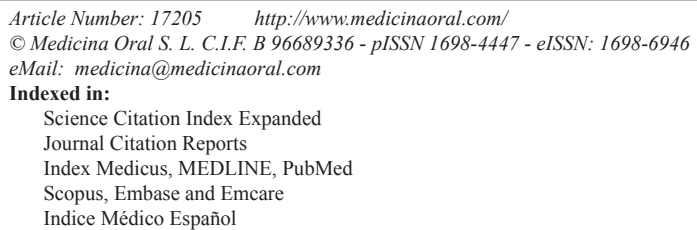

\begin{abstract}
Objectives: the expression of the osteoclastogenic cytokines TNF- $\alpha$, IL- 6 and IL- $1 \beta$ were immunohistochemically evaluated in peripheral (PGCG) and central (CGCG) giant cell granulomas of the jaws in order to determine differences between these two lesions and between the two distinct tumor cell populations (multinucleated giant cells, MGCs and stromal spindle-shaped cells).

Study Design: Paraffin-embedded tissue sections from 40 PGCG and 40 CGCG were immunohistochemically stained using antibodies against TNF- $\alpha$, IL- 6 and IL-1 $\beta$. The percentage of positively stained cells and the staining intensity were assessed to provide a combined immunoreactivity score value.

Results: TNF- $\alpha$, IL- 6 and IL-1 $\beta$ were expressed in all lesions. The CGCG compared to the PGCG showed significantly increased expression of TNF- $\alpha$ and IL- 6 and decreased expression of IL- $1 \beta$ by the spindle-shaped cells and increased expression of IL-1 $\beta$ by the MGCs. The MGCs demonstrated in comparison to the stromal spindleshaped cells significantly increased expression of all three cytokines in both PGCG and CGCG.

Conclusions: The proinflammatory cytokines TNF- $\alpha$, IL- 6 and IL-1 $\beta$ seem to be involved in the growth process of PGCG and CGCG of the jaws. A possible alteration in the synthesis or/and activity of these cytokines by the stromal spindle cells in the CGCGs may enhance osteolysis through the stimulation of osteoclast progenitor cells, given the fact that the intraosseous lesions cause bone resorption.
\end{abstract}

Key words: Giant cell granuloma, giant cell tumor, multinucleated giant cells, jaw, TNF-alpha, IL-6, IL-1beta, immunohistochemistry. 


\section{Introduction}

The central giant cell granuloma (CGCG) of the jaws represents a non-neoplastic and localized benign but sometimes aggressive osteolytic proliferation (1). This entity most commonly occurs in the mandible as an expansile radiolucency, shows variable clinical behaviour and a subset of lesions may exhibit locally aggressive growth pattern with rapid tumour enlargement associated with teeth displacement, root resorption or bone cortical perforation (2-4). The origin of CGCG is uncertain. Local trauma, inflammation, intraosseous bleeding and genetic abnormalities have been regarded as possible causes, but a unique explanation has not gained a wide acceptance (5).

The peripheral giant cell granuloma (PGCG) is an extraosseous giant cell lesion. In the oral cavity this lesion presents as a sessile or pedunculated purple-brown exophytic mass, located on the gingival or the alveolar mucosa (4). In some cases of PGCG a slight superficial (cupping) erosion of the adjacent bone can be seen radiologically (6). The exact aetiology of PGCGs still remains unclear. Developmental or/and inflammatory reactions in the periodontal ligament or the periosteum have been proposed to be involved $(4,6)$. Local irritation factors such as poor dental restorations, unstable dental prosthesis, dental extractions, plaque and calculus accumulation and food retention seem to play a significant role in the development of a PGCG (7).

The two lesions (CGCG and PGCG) demonstrate identical histopathologic features (4). They are both characterized by numerous multinucleated giant cells in a fibroblastic vascularized stroma with ovoid to spindleshaped cells which are thought to compose a heterogenous population of macrophage and fibroblastic-like cells (8).

The origin of the multinucleated giant cells (MGCs) has been a matter of considerable interest. These cells are considered to be formed from the fusion of monocyte/ macrophage precursors differentiated into osteoclasts under the influence of cytokines (8-10). The mononuclear cell component of the GCGs consists of a population of macrophage-like cells, which appears to include a subset of osteoclast precursors, and a proliferating spindle-shaped stromal cell population which has the capacity to differentiate along fibroblast/osteoblast lines. The fibroblast/osteoblast-like cells in GCGs of the jaw expressing the receptor activator of NF- $\mathrm{KB}$ ligand RANKL, which is a primary mediator of osteoclast differentiation, activation, and survival, are responsible for inducing the formation of osteoclast-like MGCs from monocytes/macrophages found in these lesions $(11,12)$. Many osteotropic hormones and cytokines have direct or indirect stimulatory and antagonistic effects on the development of the osteoclasts. TNF- $\alpha$ is a multifunctional cytokine released by activated monocytes, macrophages and $\mathrm{T}$ lymphocytes and contributes to immune responses, regulating growth, differentiation, and further production of other cytokines, inflammatory mediators and enzymes. TNF- $\alpha$ is a potent bone resorption inducer that stimulates osteoclast differentiation and activation. The proinflammatory cytokines IL-6 and IL-1 $\beta$, products of stromal cells and monocytes, stimulate in association with TNF- $\alpha$ osteoclast differentiation and activation in a synergistic fashion. These cytokines not only regulate osteoclastogenesis by stromal cells, but also act directly on osteoclasts and their precursors $(11,13,14)$.

The role of TNF- $\alpha$, IL- 6 and IL-1 $\beta$ in the pathogenesis of osteolytic lesions and diseases with pathologic bone resorption has been proved (11). These osteoclastogenic cytokines have been investigated by using various methods in giant cell tumors (GCTs) of long bones in several studies in vivo and in vitro $(8,15-17)$. The expression of TNF- $\alpha$ has also been studied in patients with giant cell lesions of the jaws $(18,19)$.

In the present study, the TNF- $\alpha$, IL- 6 and IL- $1 \beta$ expression were immunohistochemically evaluated in peripheral and central giant cell granulomas of the jaws, in order to determine possible differences between these two entities and between multinucleated giant cells and stromal spindle-shaped cells. To our knowledge, there are no studies in the English literature concerning the in situ comparative immunohistochemical expression of this triad of cytokines between the PGCG and CGCG of the jaws.

\section{Material and methods}

Study group

In this study, files of patients with a definite diagnosis of PGCG and CGCG from the Department of Oral Pathology and Medicine, Faculty of Dentistry, University of Athens were revised, the diagnosis in each case having been made on the basis of clinical, radiologic and histologic findings. Formalin-fixed and paraffin-embedded tissue samples of all the cases were retrieved. All specimens were obtained from surgical excision of the lesions and had been fixed in $10 \%$ buffered formalin. Assessment of hematoxylin and eosin-stained sections of all cases together with evaluation of clinical and radiologic data too were done so as the diagnosis of the lesions to be confirmed. Forty $(n=40)$ cases of PGCGs and forty $(n=40)$ cases of CGCGs were selected. The selection criteria included the presence in the patients' records of detailed clinical information (age, gender, anatomic location, clinical features, signs and symptoms at presentation) as well as radiographs (intraoral radiographies for the cases of PGCGs, panoramic radiographies and/ or CT scans for the cases of CGCGs). In all the cases of CGCGs, laboratory tests values for serum calcium and phosphorus concentrations, alkaline phosphatase activ- 
ity and parathyroid hormone level were also available. In all patients these parameters were within the reference ranges, excluding the occurrence of other diseases which could compromise the final diagnosis of CGCG. Most patients were females $(55 \%$ of cases with PGCG and $70 \%$ of cases with CGCG). The mean age of patients with PGCG and CGCG was 49.2 years and 45 years respectively. Both PGCG and CGCG showed a predilection for the anterior region of the mandible (75\% of PGCG and 67\% of CGCG). PGCGs mainly appeared as red pedunculated lesions with smooth surface and rubbery consistency (59\%), while in 34\% of the cases a superficial, cup-shaped radiolucency was seen radiographically. The most common clinical finding of CGCGs was bony expansion of the jaw (75\%), while in more aggressive lesions cortical perforation, tooth displacement and, rarely, pain and paresthesia were also observed. In radiographic examination, a unilocular or multilocular radiolucency was observed.

Immunohistochemistry

The immunohistochemical staining was performed on $3-5 \mu \mathrm{m}$ thick paraffin-embedded tissue sections. Sections were deparaffinized in xylene, hydrated through graded alcohol and washed with Tris-buffered saline (TBS) for $10 \mathrm{~min}$ and distilled water for another $10 \mathrm{~min}$. Endogenous peroxidase activity was blocked with $3 \%$ $\mathrm{v} / \mathrm{v} \mathrm{H}_{2} \mathrm{O}_{2}$ in water for 5-min. Antigen retrieval was performed for all antibodies by placement of the sections in citrate buffer and heating in microwave oven for 15 min. Sections were separately incubated overnight with the primary antibodies for TNF- $\alpha$ (mouse, monoclonal, HM2010, Hycult Biotech, dilution 1:10), IL-6 (goat, polyclonal, Sc1265, Santa Cruz Biotech, dilution 1:150) and IL-1 $\beta$ (mouse, monoclonal, Sc52012, Santa Cruz Biotech, dilution 1:400) and then incubated in the biotinconjugated secondary antibody for $10 \mathrm{~min}$. The standard streptavidin-biotin-peroxidase complex method was performed to bind the primary antibody with the use of a LSAB System Universal Kit (Dako) for $10 \mathrm{~min}$, DAB solution was used as chromogen for $5 \mathrm{~min}$ and all sections were counterstained with Mayer's haematoxylin for $1 \mathrm{~min}$ and mounted. Positive tissue controls included human inflamed skin for TNF- $\alpha$, glioblastoma for IL-6 and pilonidal cyst for IL-1 $\beta$. For negative controls slides the antibody was omitted.

In each section, four high-power fields were randomly selected, with a 40X magnification, and the percentage of positively stained cells (PP) of the MGCs and stromal spindle-shaped cells was assessed in each field by two observers as: $0 \quad(<10 \%$ stained cells), 1 ( $\geq 10 \%), 2$ ( $\geq 25 \%), 3(\geq 50 \%)$, and $4(\geq 75 \%)$. Staining intensity (SI) was graded as: $0=$ no expression, $1=$ weak, $2=$ moderate and $3=$ strong. The immunohistochemical expression for each cytokine was evaluated by using the scoring method ImmunoReactivity Score «IRS» $(20,21)$. According to this, the score of the percentage of stained cells (PP) for each field was multiplied by the score of the staining intensity (SI) to provide a combined immunoreactivity score value $($ IRS) $($ IRS: $\mathrm{PP} \times \mathrm{SI})$. The mean of the four fields was the IRS score for the sample.

Statistical analysis

Statistical analysis was performed by SPSS 13.0 statistical package. Because the data were conformed to abnormal distributions, the non-parametric Mann-Whitney was used. The differences were considered as statistically significant at level $\mathrm{p}=0.05$.

\section{Results}

All tumors showed similar histological features exhibiting a great number of MGCs surrounded by cell populations with oval to spindle cell morphology in a loose fibrillar connective tissue stroma with many small blood vessels. Hemosiderin (11 cases in CGCG and 7 cases

Table 1. Immunoreactivity score (IRS) values for TNF- $\alpha$, IL-6 and IL-1 $\beta$ in multinucleated giant cells and stromal spindle-shaped cells. Comparison between the peripheral and central giant cell granulomas.

\begin{tabular}{|c|c|c|c|c|}
\hline \multirow[t]{3}{*}{ Cytokine } & \multicolumn{2}{|c|}{$\begin{array}{l}\text { Peripheral Giant Cell Granuloma } \\
\qquad(n=40)\end{array}$} & \multicolumn{2}{|c|}{$\begin{array}{l}\text { Central Giant Cell } \\
\text { Granuloma }(n=40) \\
\end{array}$} \\
\hline & \multicolumn{4}{|c|}{$\begin{array}{c}\text { (number of positive cases) } \\
\text { mean IRS value } \pm \text { SD }\end{array}$} \\
\hline & $\begin{array}{l}\text { multinucleated giant } \\
\text { cells }\end{array}$ & spindle cells & $\begin{array}{l}\text { multinucleated giant } \\
\text { cells }\end{array}$ & spindle cells \\
\hline TNF- $\alpha$ & $\begin{array}{c}(n=40) \\
6.33 \pm 3.87\end{array}$ & $\begin{array}{c}(\mathrm{n}=33) \\
3.28 \pm 3.33\end{array}$ & $\begin{array}{c}(\mathrm{n}=40) \\
5.75 \pm 3,9\end{array}$ & $\begin{array}{c}(n=38) \\
* 4.18 \pm 3,21\end{array}$ \\
\hline IL-6 & $\begin{array}{c}(\mathrm{n}=40) \\
6.18 \pm 3.96 \\
\end{array}$ & $\begin{array}{c}(\mathrm{n}=36) \\
2.73 \pm 2.08 \\
\end{array}$ & $\begin{array}{c}(n=40) \\
6.05 \pm 4,01\end{array}$ & $\begin{array}{c}(\mathrm{n}=40) \\
* 4.28 \pm 2,97\end{array}$ \\
\hline IL-1及 & $\begin{array}{c}(n=40) \\
8.85 \pm 3,46\end{array}$ & $\begin{array}{c}(\mathrm{n}=34) \\
1.13 \pm 0,85\end{array}$ & $\begin{array}{c}(\mathrm{n}=40) \\
* 11.20 \pm 1,62\end{array}$ & $\begin{array}{c}(n=18) \\
* 0.45 \pm 0,5\end{array}$ \\
\hline
\end{tabular}

*statistically significant difference between peripheral and central giant cell granulomas. 
in PGCG) and bone formation demonstrating immature osteoid trabeculae surrounded by numerous osteoblasts (19 and 12 cases in CGCG and PGCG respectively) were often seen.

TNF- $\alpha$, IL- 6 and IL-1 $\beta$ were detected in all cases of PGCGs and CGCGs (Table 1). The MGCs expressed TNF- $\alpha$, IL- 6 and IL-1 $\beta$ in all cases of PGCGs and
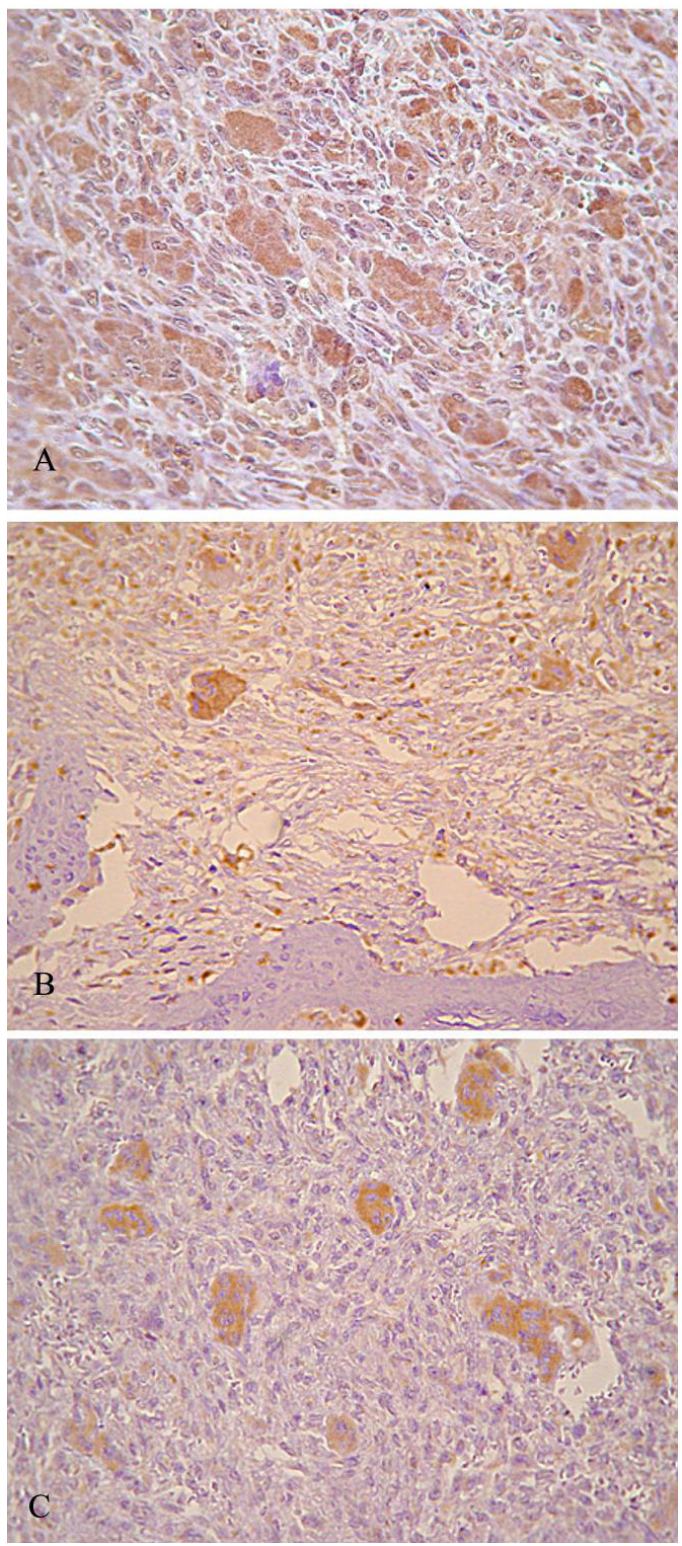

Fig. 1. (A) TNF- $\alpha$ immunohistochemical expression in PGCG (X60). Strong staining intensity of MGCs and moderate staining intensity in stromal spindle-shaped cells, (B) IL-6 immunohistochemical expression in CGCG (X60). Strong staining intensity of MGCs and moderate staining intensity in stromal spindle-shaped cells, (C) IL-1 $\beta$ immunohistochemical expression in CGCG (X120). Strong staining intensity of MGCs for IL-1 $\beta$ and no immunoreactivity in stromal spindle-shaped cells.
CGCGs as cytoplasmic immunostaining (Figure 1 $\mathrm{A}, \mathrm{B}, \mathrm{C})$. The giant cells demonstrated in comparison to the stromal spindle-shaped cells significantly increased expression of all three cytokines in both PGCG and CGCG. A variable expression for the examined cytokines was observed from the stromal spindle-shaped cells in peripheral and central lesions (Table 1). Specifically, in $95 \%$ of the central and in $82.5 \%$ of the peripheral GCGs, the spindle cells showed expression for TNF- $\alpha$ (Fig. 1A). IL-6 was expressed by the stromal spindle-shaped cells in all cases of the CGCGs (Fig. 1B) and in $90 \%$ of PGCGs, while IL-1 $\beta$ was expressed by these cells in $85 \%$ of the peripheral and $45 \%$ of the central lesions.

There was no statistically significant difference between PGCG and CGCG considering the expression of TNF- $\alpha$ and IL- 6 by MGCs, in contrast to the stromal spindle-shaped cells, which in CGCGs showed a significantly increased expression of these two cytokines (Table 1). The comparison between CGCG and PGCG considering the expression of IL- $1 \beta$ revealed that the CGCG showed significantly increased IL- $1 \beta$ expression by MGCs and decreased IL-1 $\beta$ expression by stromal spindle-shaped cells (Fig. 1C).

\section{Discussion}

The osteoclastogenic cytokines TNF- $\alpha$, IL- 6 and IL$1 \beta$ have been investigated in giant cell tumors (GCTs) of long bones. Whether the GCGs of the jaws and the GCTs of long bones are really a single pathologic process is an unanswered question. They are both characterized by the presence of MGCs, although GCTs may exhibit higher mean number of giant cells per measurement field, higher number of nuclei per giant cell, greater fractional area and relative size index and higher necrosis $(22,23)$. CGCGs, despite their reactive nature, show higher proliferative activity (24). They are much less destructive and tend to involve a younger age group (23). GCTs show neoplastic characteristics (24). They are usually painful and fast growing (5), characterized by an unpredictable biological behavior, local aggressiveness and high recurrence rates (25). The distinction between the GCGs and the GCTs may be controversial, but their histopathological and immunohistochemical similarities seem to reflect a similar pathogenesis, considered to represent a spectrum of the same disease process $(22,23)$.

To our knowledge this is the first study regarding simultaneously determination of these three proinflammatory cytokines by both MGCs and stromal spindle-shaped cells in PGCGs and CGCGs of the jaws. In a previous study, Amaral et al. (18) investigated the expression of TNF- $\alpha$ in peripheral and central giant cell lesions of the jaws and found decreased transcription of TNF- $\alpha$ genes in all the cases studied compared to healthy control sam- 
ples. In addition, De Souza et al. (19) evaluated TNF- $\alpha$ expression by circulating lymphocytes and monocytes in patients with central giant cell lesions of the jaws and found increased expression of this cytokine by CD4(+) $\mathrm{T}$ cells and decreased frequency of TNF- $\alpha+$ cells in CD68+ circulating monocytes. The authors propose that as the results of the study demonstrated an increased expression of IL-10 by monocytes and since IL-10 inhibits IL-1, IL- 6 and TNF- $\alpha$ production by activated macrophages (24), the higher expression of IL-10 could possibly explain the observed decreased frequency of TNF- $\alpha+$ cells. According to this study, it is interesting that although central giant cell lesions are localised in the jaws, they may cause significant systemic functional alterations in circulating leukocytes. Whether the central giant cell lesions may cause peripheral leukocyte activation or this activation may be caused by other factors and stimulates the formation of central giant cell lesions remains to be elucidated (19).

The results of the present study are in agreement with those found in GCTs, which show variable expression of the TNF- $\alpha$, IL- 6 and IL-1 by multinucleated giant cells and stromal spindle-shaped cells $(8,15-17)$. The TNF- $\alpha$, IL- 6 and IL-1 $\beta$ expression in peripheral and central GCGs of the jaw indicates that these cytokines are implicated in the growth process of both extraosseous and intraosseous giant cell lesions supporting the previously stated opinion that peripheral and central GCGs share similar growth potential $(26,27)$. These osteoclastogenic cytokines comprise a triad of factors that interact and may play a critical role in MGCs formation regulating the bone resorption (28), suggesting a possible synergistic role in the development of GCGs. The MGCs exhibit functional and phenotypic characteristics of osteoclasts including tartrate-resistant acid phosphatase, amino-peptidase, V-ATPase, CA II, Cathepsin K, MMP-9 and CD68, vitronectin and calcitonin receptor. The above similarities between MGCs and osteoclasts are indicative for a common histogenesis $(12,21,29)$. Recently, the study of Amaral et al. (18) in PGCGs and CGCGs showed increased transcription of the nuclear factor of activated T cells (NFATcl), which is a master of transcription in terminal differentiation of osteoclasts. These authors proposed that the development of giant cell lesions of the jaws is possibly mediated by overexpression of NFAT in the nucleus of the MGGs. In the present study, the MGCs immunostaining for TNF- $\alpha$, IL- 6 and IL- $1 \beta$ may possibly be related to osteoclast differentiation.

The spindle-shaped cells in the mononuclear cell component of the PGCG and CGCG have been proved to represent the "proliferating compartment" considered responsible for the biologic activity of these tumors. These mesenchymal in origin cells resembling immature osteoblasts release a wide range of factors (recep- tor activator of NF- $\mathrm{B}$ ligand - RANKL, interleukines, interferon gamma - IFN- $\gamma$, macrophage-colony stimulating factor - MCSF, granulocyte-macrophage colony stimulating factor - GMCSF) that recruit monocytes/ osteoclast precursors and promote their differentiation into functional osteoclasts $(8,21,26-28)$. In the present study, the comparison between the peripheral and central GCGs revealed that in the CGCG there was a statistically significant increased expression of TNF- $\alpha$ and IL- 6 by the spindle cells, but not by the MGCs. TNF- $\alpha$ is responsible for stimulating osteoclastic bone resorption in vitro as well as in vivo $(11,14)$. IL-6 is known to stimulate mesenchymal progenitor differentiation toward the osteoblastic lineage and is also a potent antiapoptotic agent on osteoblastic cells. The main sources of IL-6 in bone are osteoblastic cells, stromal cells and not osteoclastic cells, but the activity of IL- 6 on bone is its effect on osteoclastogenesis (11).

In contrast to the increased expression of TNF- $\alpha$ and IL- 6 by the spindle cells in our study, the CGCG showed significantly increased IL-1 $\beta$ expression by the MGCs and decreased IL-1 $\beta$ expression by the stromal spindleshaped cells. Gamberi et al. (15) by using immunohistochemistry and real-time quantitative PCR techniques found increased expression of IL-6 in GCTs associated with higher biological aggressiveness, but without any significant differences between the two cell populations. Increased expression of TNF- $\alpha$, IL-1 and IL-6 mRNA by stromal cells has been observed in GCTs by Atkins et al (16). On the other hand, immunoreactivity for IL-1 $\beta$, IL- 6 and TNF- $\alpha$ also confirmed by in situ hybridization was mainly observed in giant cells, whereas stromal cells showed scattered staining in GCTs (17).

Regezi (26) speculates that the subset of CGCGs that show a locally aggressive behaviour may develop from a reactive lesion through an epigenetic event occurring in spindle-shaped mesenchymal cells of bone resulting in escape from cell cycle controls and in expression of proteins capable of monocyte recruitment and differentiation into MGCs. Osteoclastic differentiation is controlled by complex interactions between OPG, RANK and RANKL. OPG and RANKL are synthesized by stromal cells/osteoblasts, while RANK is localized at the cell surface of mature osteoclasts and osteoclastic precursors. OPG inhibits osteolysis and blocks RANKL/RANK interaction. TNF- $\alpha$, IL-6 and IL-1 may also play a role in the osteoclastic differentiation and increase production of both RANKL and OPG. These cytokines also act directly on osteoclasts and their precursors and additionally they have an important effect in stimulating RANKL production by osteoblastic cells and in acting synergistically with RANKL (11).

The results of the present study showed that the stromal spindle-shaped cells in CGCGs demonstrated increased TNF- $\alpha$, IL- 6 and decreased IL-1 $\beta$ immunohistochemi- 
cal expression compared to the PGCGs. Although, immunohistochemical overexpression may not necessarily reflect overproduction of these osteoclastogenic molecules by the spindle cells in CGCGs, a possible alteration in the synthesis or/and activity of these regulatory cytokines within the bone microenvironment may enhance osteolysis through the stimulation of osteoclast progenitor cells, given the fact that intraosseous lesions cause bone resorption. The MGCs in PGCG may occasionally show bone resorptive capacity adjacent to the lesion. The cellular composition in PGCG has been showed to be similar with that in giant cell lesions of different sites and MGCs express the same osteolytic proteases and osteoclast-activating cytokines involved in bone metabolism (30). In PGCG, the TNF- $\alpha$, IL-6 and IL- $1 \beta$ interrelations may control the cellular activities of the different cell populations (multinuclear cells, monocytes/macrophages, spindle fibroblasts/osteoblasts) contributing possibly mainly in the mechanisms of tumor growth, and occasionally of osteolysis. Friedrich et al. (30) analyzed the expression of proteases relevant for osteolysis in giant cell lesions and showed that despite of the strong cathepsin K expression by the MGCs in PGCGs, there was no radiological evidence for jaw osteolysis adjacent to the examined lesions. According to these authors, the capacity of cathepsin $\mathrm{K}$ to degrade bone seems to be related not to the high amounts of this protein in giant cells, but to the topography of the lesion in relation to the adjacent bone, since osteoclasts more distantly located to bone may contain an inactive form (procathepsin $\mathrm{K}$ ) and not the mature, active cathepsin $\mathrm{K}$.

In conclusion, the proinflammatory cytokines TNF- $\alpha$, IL- 6 and IL-1 $\beta$ seem to be involved in the growth process of peripheral and central GCGs of the jaws. Further studies are necessary to clarify the functional role of these cytokines in the development of PGCGs and CGCGs and to determine whether control over these proteins may provide another strategy for future medical treatment of these tumors.

\section{References}

References with links to Crossref - DOI

1. Potter BJ, Tiner BD. Central giant cell granuloma. Report of a case. Oral Surg Oral Med Oral Pathol. 1993;75:286-9.

2. Kruse-Lösler B, Diallo R, Gaertner C, Mischke KL, Joos U, Kleinheinz J. Central giant cell granuloma of the jaws: a clinical, radiologic, and histopathologic study of 26 cases. Oral Surg Oral Med Oral Pathol Oral Radiol Endod. 2006;101:346-54.

3 . Horner K. Central giant cell granuloma of the jaws: a clinico-radiological study. Clin Radiol. 1989;40:622-6.

4. Motamedi MH, Eshghyar N, Jafari SM, Lassemi E, Navi F, Abbas FM, et al. Peripheral and central giant cell granulomas of the jaws: a demographic study. Oral Surg Oral Med Oral Pathol Oral Radiol Endod. 2007;103:e39-43.

5. Lin YJ, Chen HS, Chen HR, Wang WC, Chen YK, Lin LM. Central giant cellgranuloma of the mandible in a 7-year-old boy: a case report. Quintessence Int.2007;38:253-9.
6. Katsikeris N, Kakarantza-Angelopoulou E, Angelopoulos AP. Peripheral giant cell granuloma. Clinicopathologic study of 224 new cases and review of 956 reported cases. Int J Oral Maxillofac Surg. 1988;17:94-9.

7. Chaparro-Avendaño AV, Berini-Aytés L, Gay-Escoda C. Peripheral giant cell granuloma. A report of five cases and review of the literature. Med Oral Patol Oral Cir Bucal. 2005;10:53-7; 48-52.

8. Liu B, Yu SF, Li TJ. Multinucleated giant cells in various forms of giant cell containing lesions of the jaws express features of osteoclasts. J Oral Pathol Med. 2003;32:367-75.

9. Bonetti F, Pelosi G, Martignoni G, Mombello A, Zamboni G, Pea $\mathrm{M}$, et al. Peripheral giant cell granuloma: evidence for osteoclastic differentiation. Oral Surg Oral Med Oral Pathol. 1990;70:471-5.

10. Helming L, Gordon S. The molecular basis of macrophage fusion. Immunobiology. 2007;212:785-93.

11. Kwan Tat S, Padrines M, Théoleyre S, Heymann D, Fortun Y. IL-6, RANKL, TNF-alpha/IL-1: interrelations in bone resorption pathophysiology. Cytokine Growth Factor Rev. 2004;15:49-60.

12. Itonaga I, Hussein I, Kudo O, Sabokbar A, Watt-Smith S, Ferguson D, et al. Cellular mecha-nisms of osteoclast formation and lacunar resorption in giant cell granuloma of the jaw. J Oral Pathol Med. 2003;32:224-31

13. Ma T, Miyanishi K, Suen A, Epstein NJ, Tomita T, Smith RL, et al. Human interleukin-1-induced murine osteoclastogenesis is dependent on RANKL, but independent of TNF-alpha. Cyto-kine. 2004;26:138-44.

14. Fuller K, Murphy C, Kirstein B, Fox SW, Chambers TJ. TNFalpha potently activates osteo-clasts, through a direct action independent of and strongly synergistic with RANKL. Endocrinolo-gy. 2002;143:1108-18.

15. Gamberi G, Benassi MS, Ragazzini P, Pazzaglia L, Ponticelli F, Ferrari C, et al. Proteases and interleukin- 6 gene analysis in 92 giant cell tumors of bone. Ann Oncol. 2004:15:498-503.

16. Atkins GJ, Haynes DR, Graves SE, Evdokiou A, Hay S, Bouralexis $\mathrm{S}$, et al. Expression of oste-oclast differentiation signals by stromal elements of giant cell tumors. J Bone Miner Res. 2000;15:640-9.

17. O'Keefe RJ, Teot LA, Singh D, Puzas JE, Rosier RN, Hicks DG. Osteoclasts constitutively ex-press regulators of bone resorption: an immunohistochemical and in situ hybridization study. Lab Invest. 1997;76:457-65.

18. Amaral FR, Brito JA, Perdigão PF, Carvalho VM, de Souza PE, Gomez MV, et al. NFATc1 and TNFalpha expression in giant cell lesions of the jaws. J Oral Pathol Med. 2010;39:269-74.

19. de Souza PE, Gomez RS, Xavier GM, dos Santos JS, Gollob KJ, Dutra WO. Systemic leuko-cyte activation in patients with central giant cell lesions. J Oral Pathol Med. 2005;34:312-7.

20. Remmele W, Stegner HE. Recommendation for uniform definition of an immunoreactive score (IRS) for immunohistochemical estrogen receptor detection (ER-ICA) in breast cancer tissue. Pathologe. 1987;8:138-40.

21. Tobón-Arroyave SI, Franco-González LM, Isaza-Guzmán DM, Floréz-Moreno GA, Bravo-Vásquez T, Castañeda-Peláez DA, et al. Immunohistochemical expression of RANK, GRalpha and CTR in central giant cell granuloma of the jaws. Oral Oncol. 2005;41:480-8. 22. Auclair PL, Cuenin P, Kratochvil FJ, Slater LJ, Ellis GL. A clinical and histomorphologic comparison of the central giant cell granuloma and the giant cell tumor. Oral Surg Oral Med Oral Pathol. 1988;66:197-208.

23. Saw S, Thomas N, Gleeson MJ, Bódi I, Connor S, Hortobágyi T. Giant cell tumour and central giant cell reparative granuloma of the skull: do these represent ends of a spectrum? A case report and literature review. Pathol Oncol Res. 2009;15:291-5.

24. de Souza PE, Paim JF, Carvalhais JN, Gomez RS. Immunohistochemical expression of p53, MDM2, Ki-67 and PCNA in central giant cell granuloma and giant cell tumor. J Oral Pathol Med. 1999;28:54-8. 
25. Aragão Mdo S, Piva MR, Nonaka CF, Freitas Rde A, de Souza LB, Pinto LP. Central giant cell granuloma of the jaws and giant cell tumor of long bones: an immunohistochemical comparative study. J Appl Oral Sci. 2007;15:310-6.

26. Regezi JA. Comments on the pathogenesis and medical treatment of central giant cell granulo-mas. J Oral Maxillofac Surg. 2004;62:116-8.

27. Lau YS, Sabokbar A, Gibbons CL, Giele H, Athanasou N. Phenotypic and molecular studies of giant-cell tumors of bone and soft tissue. Hum Pathol. 2005;36:945-54.

28. Dai JC, He P, Chen X, Greenfield EM. TNFalpha and PTH utilize distinct mechanisms to in-duce IL-6 and RANKL expression with markedly different kinetics. Bone. 2006;38:509-20.

29. Mills BG, Frausto A. Cytokines expressed in multinucleated cells: Paget's disease and giant cell tumors versus normal bone. Calcif Tissue Int. 1997;61:16-21

30. Friedrich RE, Eisenmann J, Röser K, Scheuer HA, Löning T. Expression of proteases in giant cell lesions of the jaws, tendon sheath and salivary glands. Anticancer Res. 2010;30:1645-52.

\section{Acknowledgements}

Supported by the Special Account for Research Grants of the National and Kapodistrian University of Athens, Greece (NKUA/SARG, code $70 / 4 / 8894)$ 